\title{
Low-Cost Wavelength Measurement Based on a Macrobending Single-Mode Fiber
}

\author{
Qian Wang \\ Technological University Dublin, qian.wang@tudublin.ie \\ Gerald Farrell \\ Technological University Dublin, gerald.farrell@tudublin.ie \\ Thomas Freir \\ Technological University Dublin, thomas.freir@tudublin.ie
}

See next page for additional authors

Follow this and additional works at: https://arrow.tudublin.ie/engscheceart

Part of the Electrical and Computer Engineering Commons

\section{Recommended Citation \\ Wang, Q., Farrell,G., Freir,T.,Rajan, G., Wang, P.: Low-cost wavelength measurement based on a macrobending single-mode fiber. Optics Letters, Vol.31 (12), 2006, pp.1785-1787. doi;10.1364/ OL.31.001785}

This Article is brought to you for free and open access by the School of Electrical and Electronic Engineering at ARROW@TU Dublin. It has been accepted for inclusion in Articles by an authorized administrator of ARROW@TU Dublin. For more information, please contact arrow.admin@tudublin.ie, aisling.coyne@tudublin.ie, gerard.connolly@tudublin.ie.

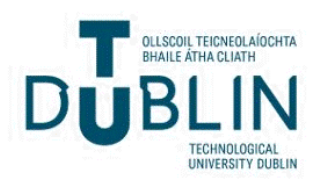


Authors

Qian Wang, Gerald Farrell, Thomas Freir, Ginu Rajan, and Pengfei Wang

This article is available at ARROW@TU Dublin: https://arrow.tudublin.ie/engscheceart/64 


\title{
Low-cost wavelength measurement based on a macrobending single-mode fiber
}

\author{
Qian Wang, Gerald Farrell, Thomas Freir, Ginu Rajan, and Pengfei Wang \\ Applied Optoelectronics Centre, School of Electronics and Communications Engineering, \\ Dublin Institute of Technology, Kevin Street, Dublin 8, Ireland
}

\begin{abstract}
Received January 31, 2006; revised March 6, 2006; accepted March 23, 2006; posted March 28, 2006 (Doc. ID 67640) A low-cost all-fiber wavelength measurement technique is proposed and demonstrated. A macrobending standard single-mode fiber is developed as an edge filter with an optimal design and simple surface processing. A ratiometric wavelength measurement system employing the developed macrobending fiber filter demonstrates a resolution of $\sim 10 \mathrm{pm}$ in a wavelength range from 1500 to $1560 \mathrm{~nm}$ with ease of assembly and calibration. (C) 2006 Optical Society of America

OCIS codes: $060.2370,120.2440,120.1880$.
\end{abstract}

The measurement of an unknown wavelength is a common operation for many optical systems. Examples include wavelength monitoring in multichannel dense wavelength division multiplexing (DWDM) optical communication systems and optical sensing systems based on fiber Bragg gratings (FBGs) or Fabry-Perot (FP) filters. DWDM requires the accurate setting and maintaining of the transmitter's wavelength or monitoring of the tunable laser's wavelength. ${ }^{1,2}$ An FBG- or FP-filter-based optical sensing system requires a wavelength demodulation system to detect the wavelength shift of reflected light, which is crucial in the successful implementation of the above optical sensing techniques. ${ }^{3}$

This Letter proposes and demonstrates a simple all-fiber ratiometric wavelength measurement scheme in which a macrobending single-mode fiber is utilized as an edge filter [see Fig. 1(a)]. As compared with the existing active wavelength scanning techniques, it has a simple configuration, requiring no mechanical movement and offering a potential for high-speed measurement. ${ }^{4,5}$ This all-fiber wavelength measurement technique has the superior characteristics of easy interconnection, mechanical stability, and low polarization dependence as compared with ratiometric systems involving bulk filters or integrated optical waveguide based filters. ${ }^{6-8}$

For the macrobending single-mode fiber, most of the previously published investigations focused on how to predict and lower the bend loss, which is regarded as an adverse effect for light transmission. There are also some studies employing bent fibers as optical sensing elements. The wavelength dependence of a bending fiber was presented as an existing phenomenon in some of the literature, ${ }^{9,10}$ but there have been very few investigations that employ this wavelength-dependent characteristic for practical applications; it was used as a wavelength demultiplexer in Ref. 11. In this Letter, with an optimal design and simple surface processing, a macrobending standard single-mode fiber (SMF28) is developed as an edge filter and introduced to the ratiometric wavelength measurement system for the first time to the best of our knowledge. As compared with the existing wavelength-division-coupler- or bioconical-fiberfilter-based ratiometric wavelength measure- ments, ${ }^{12,13}$ the macrobending-fiber-based edge filter has a lower fabrication cost while offering flexible discrimination and a measurable wavelength range through the adjustment of the length of macrobending section.

For a ratiometric wavelength measurement system with a measurable wavelength range from $\lambda_{1}$ to $\lambda_{2}$, an edge filter with a low baseline transmission loss at $\lambda_{1}\left(\lambda_{2}\right)$ and an appropriate discrimination of transmission loss over the wavelength range is desired [see Fig. 1(b)], with consideration given to the precision and the range of practical optical power measurements of the employed photodetectors and the limited signal-to-noise ratio of measured source. ${ }^{14} \mathrm{As}$ a design and experimental example, a ratiometric wavelength measurement system with a measurable wavelength range from 1500 to $1560 \mathrm{~nm}$ is considered. The desired discrimination in the present paper is chosen to be about $20 \mathrm{~dB}$ with a transmission loss less than $30 \mathrm{~dB}$ over the whole wavelength range.

It is known that for an optical waveguide with an infinite cladding the bend loss will increase as the bending radius decreases. However, a practical fiber contains one or two coating layers outside to offer mechanical protection. Because of the reflection of the radiated field at the interface between the cladding layer and the coating layer, a so-called whisperinggallery mode is produced, and the fiber shows significantly different bend loss characteristics as compared with the simple case of infinite cladding outside. . $^{1,15-17}$

For this SMF28 fiber, the refractive indices for the core, cladding, inner coating, and outer coating layer at wavelength $1.55 \mu \mathrm{m}$ are $1.4504,1.4447,1.4786$,

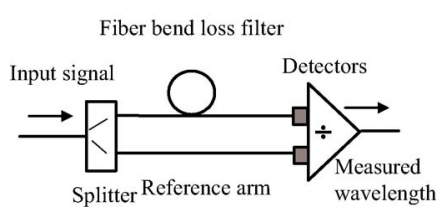

(a)

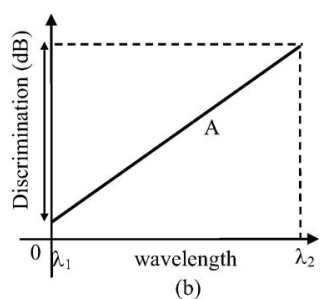

Fig. 1. (a) Schematic configuration of the ratiometric wavelength measurement system with the fiber bend loss filter; (b) desired spectral response of the fiber filter. 


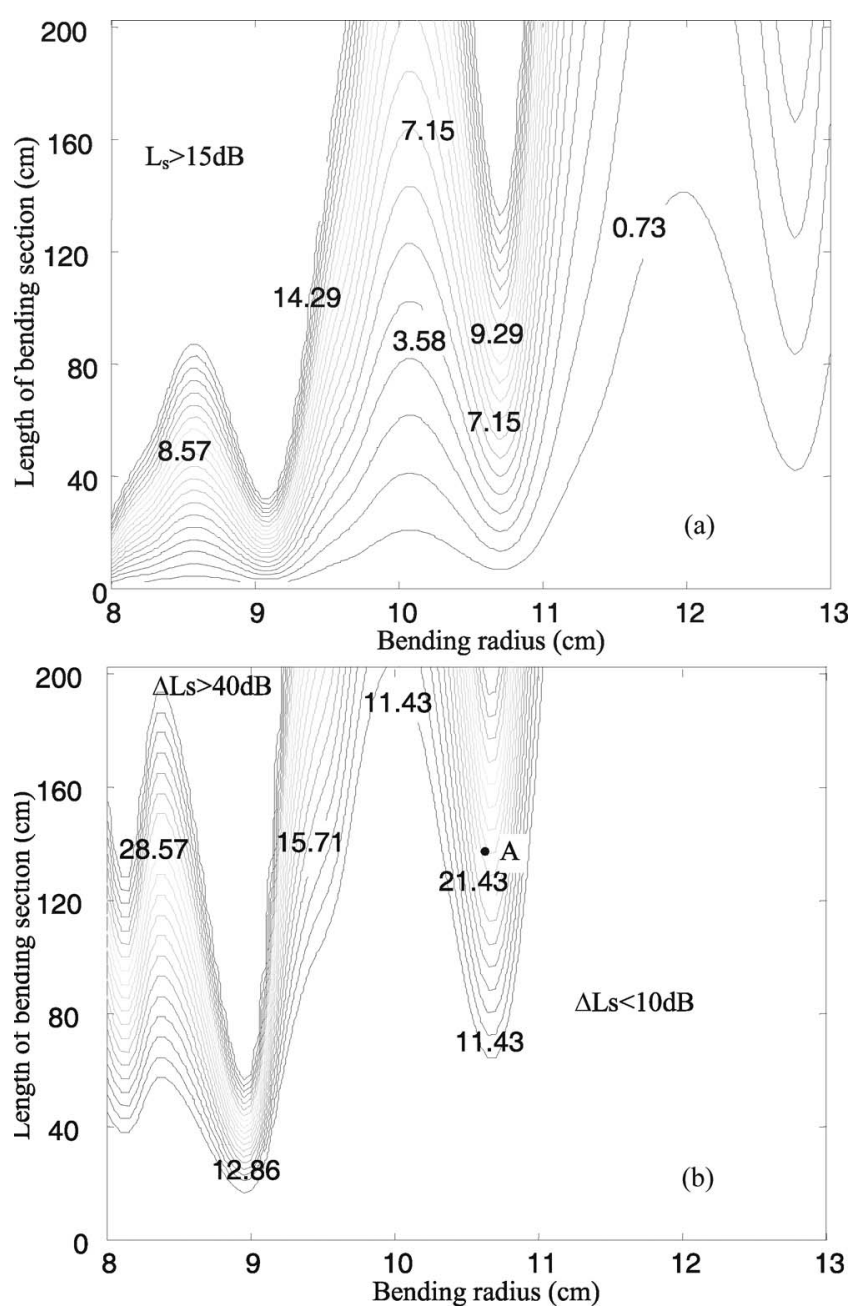

Fig. 2. (a) Contour plot of bending loss versus length of bending section and bending radius at the wavelength $1500 \mathrm{~nm}$; (b) contour plot of $\Delta L_{s}$ versus length of bending section and bending radius.

and 1.5294, respectively. The corresponding diameters are 8.3, 125, 190, and $250 \mu \mathrm{m}$, respectively. Based on the theoretical model presented in Ref. 17, a contour plot for the macrobending loss $L_{s}$ under different bending radii and lengths for wavelength $\lambda$ $=1500 \mathrm{~nm}$ is shown in Fig. 2(a), from which one can see that, owing to the whispering-gallery mode, the bend loss does not increase monotonically as the bending radius decreases. For example, bend losses for a bending radius of $9 \mathrm{~mm}$ are bigger than those for a bending radius of $8.5 \mathrm{~mm}$. The discrimination, that is, the difference in the bend loss $\Delta L_{s}$ between 1500 and $1560 \mathrm{~nm}$, is also calculated and presented in Fig. 2(b). According to the above desired discrimination over the wavelength range from 1500 to $1560 \mathrm{~nm}$, by combining the two contour plots of Figs. 2(a) and 2(b), the optimal bending radius and length can be determined.

The selection of the correct bend parameters, that is, bending radius and bending length, from Figs. 2(a) and 2(b) does involve a compromise in that achieving a very low baseline attenuation (e.g., $<3 \mathrm{~dB}$ ) will restrict the discrimination available to $<10 \mathrm{~dB}$. Conversely, selecting a discrimination greater than, e.g., $30 \mathrm{~dB}$ results in a baseline attenuation of $>15 \mathrm{~dB}$. Therefore from these two contour plots we select region A [Fig. 2(b); the bending radius is about $10.8 \mathrm{~cm}$, and the length is about $140 \mathrm{~mm}$ ], which shows suitable characteristics (a baseline transmission loss of about $10 \mathrm{~dB}$ at $1500 \mathrm{~nm}$ and a discrimination range of about $20 \mathrm{~dB}$ at $1560 \mathrm{~nm}$ ). To investigate the transmission spectrum over the whole wavelength range, an experiment setup involving a tunable laser and an optical spectrum analyzer was built, and bend losses for SMF28 were measured. Bend losses for bending radii of 10, 10.5, 11, and $11.5 \mathrm{~mm}$ with a bending length of 22 turns are presented in Fig. 3(a).

The measured bend loss basically increases as the wavelength increases with some random variations rather than in a strict monotonic increase. Furthermore, the measured results are not exactly repeatable and differ for each measurement run. This phenomenon can be explained: in the bending case, when the radiated field escapes from the cladding layer, some of radiated field is reflected and forms the whispering-gallery mode, and the rest penetrates into the coating layers. Most of the penetrated radiated field is absorbed or scattered in the coating layers, and a small amount of the radiated field reaches the fiber surface. Because of the strong reflection at the interface between the outer primary coating layer and air (about 1.5/1.0), the reflected field affects the transmission of the bending fiber. To remove these random variations to make the fiber suitable for wavelength measurement applications, an absorbing outside coating layer is added, and the bend loss is measured again with the same bending radii and lengths. Corresponding results are presented in Fig. 3(b). As compared with the measured bend loss in Fig. 3(a), the random variations disappear, which indicates that these random variations are caused by the reflection that occurs at the interface between the outer coating layer and air. The measured bend loss increases strictly as the wavelength increases, and it makes this macrobending single-mode fiber filter suitable for wavelength measurement. The transmission spectrum for a bend radius of $11 \mathrm{~mm}$ (the bend loss is about $12.5 \mathrm{~dB}$ at wavelength $1500 \mathrm{~nm}$ and the discrimination is about $16 \mathrm{~dB}$ ) is chosen in the following demonstration.

With the above developed macrobending fiber filter, a ratiometric wavelength measurement system is built as shown in Fig. 1(a). The input light signal is split into two equal signals with a $3 \mathrm{~dB}$ beam splitter. One passes through a reference arm, and the other passes through the fiber bend loss filter. Two photodiodes are placed at the ends of both arms. By measuring the ratio of the electrical outputs of the two photodiodes, the wavelength of the input signal can be determined, assuming suitable calibration has taken place. While the length of the bending section is an important parameter, it is not necessary in practice to get the length precisely right, provided the system is calibrated after setup.

Resolution for a ratiometric wavelength measurement system, i.e., the minimum wavelength shift it 
can detect in practical applications, is an important characteristic when the system is used for monitoring a tunable laser or in a FBG- or FP-based sensing system. In order to investigate the resolution of the developed ratiometric wavelength measurement system, it is used to detect the wavelength shift of the input signal from a tunable laser in our demonstration, and the corresponding output (ratio of the two outputs from the photodetectors) is recorded. A set of corresponding experimental results for the tunable laser wavelength of $\sim 1550 \mathrm{~nm}$ is shown in Fig. 4, where the wavelength is stepped by $10 \mathrm{pm}$ every $8-10 \mathrm{~s}$. The tuning step of $10 \mathrm{pm}$ is the minimum available tuning step for the laser used. The clearly detectable change of the recorded output of the system shows a resolution of better than $10 \mathrm{pm}$, which is competitive as compared with some active wavelength scanning techniques, with the advantages of robustness and no mechanical movement.

In this Letter we have proposed a low-cost all-fiber wavelength measurement technique based on a macrobending single-mode fiber. Design and fabrication of the fiber bend loss filter with SMF28 has been presented. A wavelength measurement system has been demonstrated, and a resolution of better than $10 \mathrm{pm}$
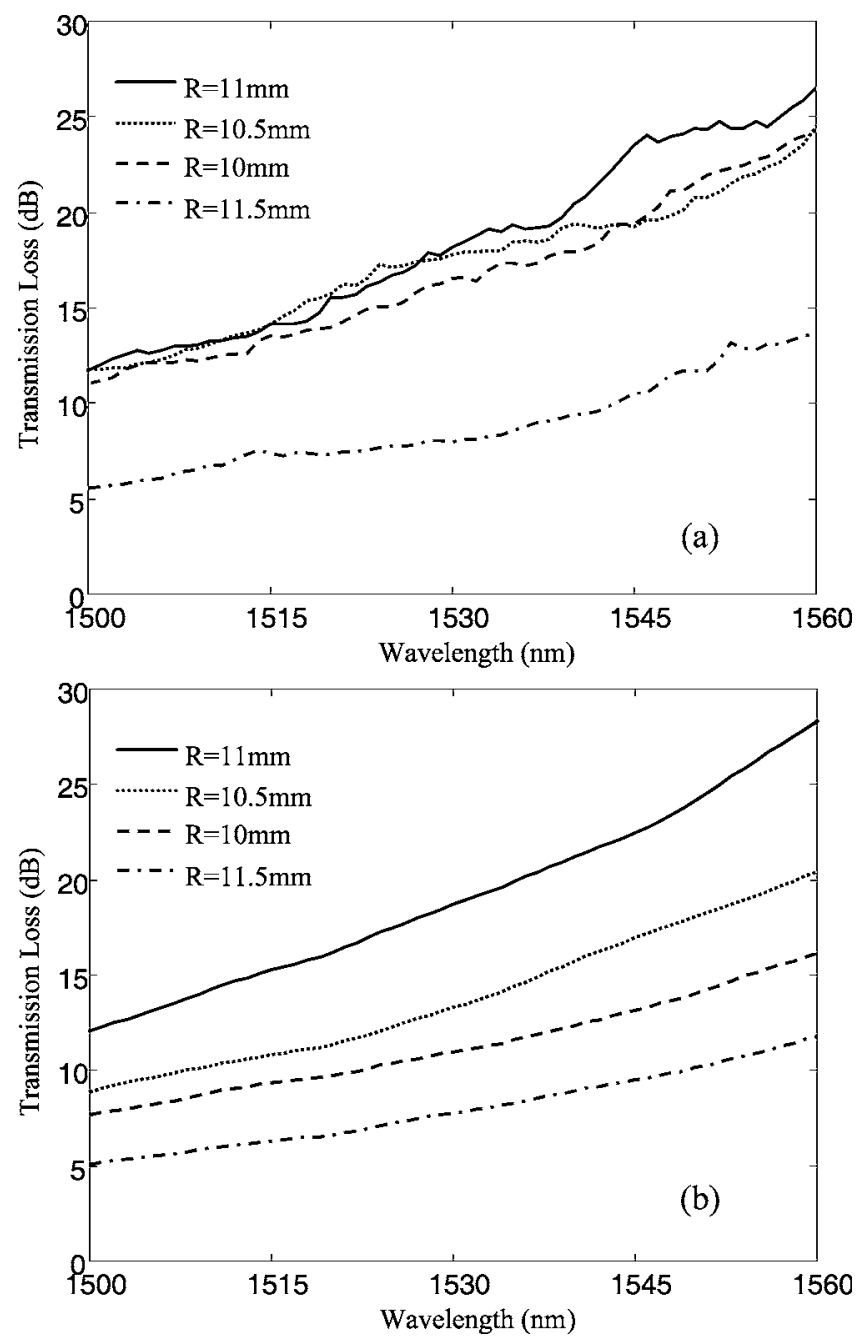

Fig. 3. (a) Measured transmission loss of bending SMF28; (b) measured transmission loss of bending SMF28 with an absorbing coating layer outside.

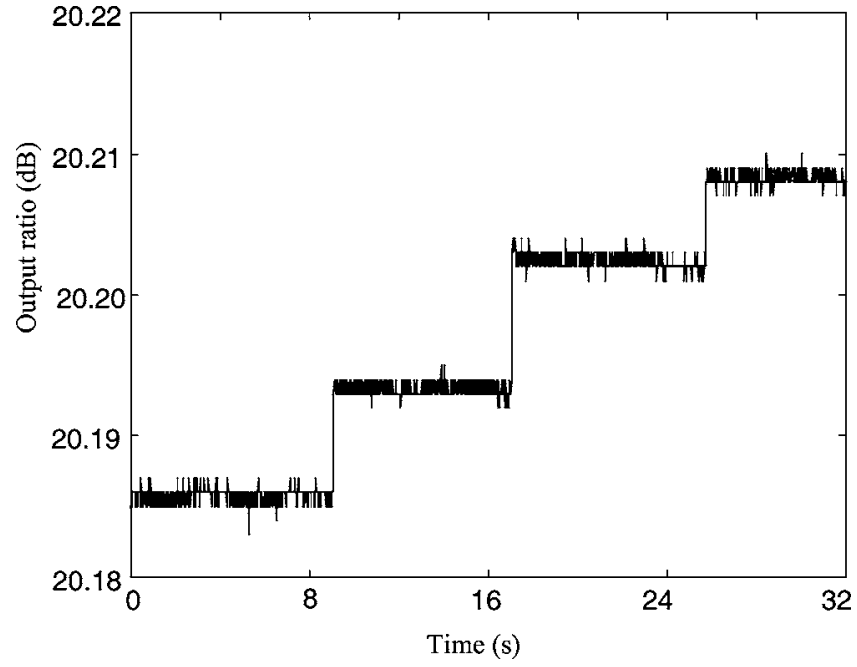

Fig. 4. Measured output of the ratiometric system as the input signal increases by $10 \mathrm{pm}$.

in a wavelength range from 1500 to $1560 \mathrm{~nm}$ has been achieved. This technique can be employed in DWDM optical communications and FBG- or FPfilter-based optical sensing systems for wavelength detection.

Q. Wang's e-mail address is Qian.wang@dit.ie.

\section{References}

1. B. Mason, S. P. DenBaars, and L. A. Coldren, IEEE Photon. Technol. Lett. 10, 1085 (1998).

2. J. J. Lepley and A. S. Siddiqui, IEE Proc. Optoelectron. 146, 121 (1999).

3. A. D. Kersey, M. A. Davis, H. J. Patrick, M. Leblanc, K. P. Koo, C. G. Askin, M. A. Putnam, and E. J. Friebele, J. Lightwave Technol. 15, 1442 (1997).

4. K. B. Rochford and S. D. Dyer, J. Lightwave Technol. 17, 831 (1999).

5. J. Jiang, T. Liu, Y. Zhang, L. Liu, Y. Zha, F. Zhang, Y. Wang, and P. Long, Opt. Lett. 30, 604 (2005).

6. S. M. Melle, K. Liu, and R. M. Measures, IEEE Photon. Technol. Lett. 4, 516 (1992).

7. C. Sookdhis, T. Mei, H. S. Djie, and J. Arokiaraj, Opt. Eng. 42, 3421 (2003).

8. G. Z. Xiao, P. Zhao, F. G. Sun, Z. G. Lu, Z. Zhang, and C. P. Grover, Opt. Lett. 29, 2222 (2004).

9. R. Morgan, J. S. Barton, P. G. Harper, and J. D. C. Jones, Opt. Lett. 15, 947 (1990).

10. L. Faustini and G. Martini, J. Lightwave Technol. 15, 671 (1997).

11. A. J. Harris, P. A. Shrubshall, and P. F. Castle, J. Lightwave Technol. 6, 80 (1988).

12. M. A. Davis and A. D. Kersey, Electron. Lett. 30, 75 (1994).

13. A. B. L. Ribeiro, L. A. Ferreira, M. Tsvetkov, and J. L. Santos, Electron. Lett. 32, 382 (1996).

14. Q. Wang, G. Farrell, and T. Freir, Appl. Opt. 44, 7789 (2005).

15. H. Renner, J. Lightwave Technol. 10, 544 (1992).

16. I. Valiente and C. Vassallo, Electron. Lett. 25, 1544 (1989).

17. Q. Wang, G. Farrell, and T. Freir, Opt. Express 13, 4476 (2005). 